\title{
ACR
}

Selected Papers of \#AoIR2020:

The $21^{\text {st }}$ Annual Conference of the

Association of Internet Researchers

Virtual Event / 27-31 October 2020

\section{RENAME AND RESIST COLONIAL EXTRACTION: TWITTER'S TOPONYMIC POLITICS}

\author{
Carrie Karsgaard \\ University of Alberta \\ Maggie MacDonald \\ University of Toronto \\ Michael Hockenhull \\ IT University of Copenhagen
}

Canada, known to many Indigenous peoples as Turtle Island, has seen a surge of (re)naming and land acknowledgement, which draws attention to Indigenous stewardship and territories, which have been overwritten through colonial mapping and naming practices. Renaming is not limited to physical spaces, but it also occurs virtually. On Twitter, profiles of users are free-form and can be associated with "official," colonial names like Vancouver or Ottawa. However, Twitter's open location field also enables users to situate themselves by Indigenous place names or locations suggesting anticolonial positioning, such as "Secwepemcul'ecw" and "Occupied Syilx Territory." Our project explores subversive (re)naming practices on Twitter to address: what is the nature of Indigenous and anti-colonial toponymic identification among Twitter users in Canada? Writing together as two settler scholars and another from Denmark as a stranger to the lands discussed in this paper, ours is an attempt to engage toponymic resistance in an everyday, virtual, social space where we participate as relations, citizens, creators, information sharers, and fellows outside of institutional boundaries. A focus on toponymy rather than identity is also an opportunity to consider "place-based solidarities" (Snelgrove, Dhamoon, \& Corntassel, 2014, p. 14) that unsettle settler colonialism on Twitter.

\section{Settler Colonialism and Virtual Toponymy}

Critical toponymy identifies how naming practices are slippery, insofar as they appear neutral or natural, when in reality they relay hegemonic structures and are mechanisms of classification and control (Rose-Redwood et al., 2010). In settler-colonial contexts, Karsgaard, C., MacDonald, M., \& Hockenhull, M. (2020, October). Rename and resist colonial extraction: Twitter's Toponymic Politics. Paper presented at AolR 2020: The $21^{\text {th }}$ Annual Conference of the Association of Internet Researchers. Virtual Event: AolR. Retrieved from http://spir.aoir.org. 
toponyms are tools of erasure, where colonial toponymy overwrites epistemologies, languages, histories, and relationships, so as a resurgent practice, place naming can be an assertion of ongoing Indigenous presence on the land (apihtawikosis`an, 2016), articulating Indigenous knowledge systems, cultures, and connections to place. We argue that geographic information systems (GIS), standardized domain naming, and other virtual locative technologies function similarly to what Rose-Redwood et al. (2010) term "calculable spaces"; they may be used to regulate representation and communication, and be used for data gathering and social control.

Platforms have become infrastructures of communication, and social media networks in particular provide a discursive space, embedded in public life and informing our sociopolitical experience (Plantin et al. 2018, van Dijck et al., 2019). The boundaries and affordances of platforms are key to understanding them as infrastructures in relation to social life. Twitter's free-form location field is a technological affordance that allows for greater scope than pre-set calculable locations or GIS. Rather than static and standardized, Twitter's malleable and emergent naming options creates opportunities for politically resistant expression, affording users possibilities for anti-colonial toponymy.

\section{Methodology}

We apply a digital methods approach (Rogers, 2013), which repurposes the tools embedded in platforms for social research. To narrow our sample, we focused on profiles of Twitter users who tweeted about the Trans Mountain pipeline, a controversial infrastructure project that conflicts with many Indigenous people's lifeways, sovereignty, and claims to land. Pipeline-associated tweets were extracted via the Digital Methods Initiative-Twitter Capture and Analysis Toolset (Borra \& Rieder, 2014) from 26 June 2018 to 7 July 2018, totaling 27,000 tweets from 13,000 users. We sorted user profile locations to identify tweets produced by users situated in various locations in Canada, which we then manually sorted according to Indigenous and anti-colonial identifiers in the broadest sense, resulting in a subset of 576 tweets. To be identified as Indigenous or anti-colonial, a toponym utilized an Indigenous language, referenced an Indigenous territory (whether Indigenous or state-defined), drew attention to colonial relations, or resisted colonial naming practices. Utilizing this smaller data set, we developed an untypology of patterns of resistant naming practices and land acknowledgement on the platform.

\section{Un-Typology of Twitter Toponyms}

Not only do Twitter users make use of the free-form field for Indigenous and anticolonial place names, but they do so in ways that defy simple and artificial categorization, capturing multiple ways of conceptualizing location.

Most location identifiers reference Indigenous territories and lands, such as "K'omoks/Pentlatch Territory" and "Muwekma Ohlone Land," at times modified by the terms "ancestral" or "traditional," which allude to the historic and enduring nature of Indigenous territories. Some draw attention to the connection between territory and specific Indigenous groups, through phrases that bind land with human communities, like the "traditional territories of the Snuneymuxw people." The connections between culture, land, and knowledge can be seen where territories are indicated in Indigenous 


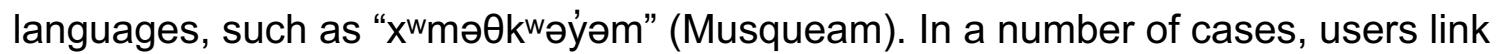
territory with multiple peoples whose territories overlap, as in "Musqueam, Tsleil Waututh, and Squamish Territory." A noticeable number of users list colonial and Indigenous toponyms together, as in "Lekwungen Territory/Victoria," marking the coexistence of Indigenous and colonial authority. The intermingling of state and Indigenous toponyms evidences how lands are at once demarcated for colonial governance and also remain homelands for occupied peoples.

Colonial relations are made explicit by referencing treaties or lack thereof on specific lands. By listing "Treaty 6," for instance, users indicate legal relations between Indigenous people and the Government of Canada (though the nature of these relations is contested). Modifying an Indigenous territory with the word "unceded," as in "Unceded Secwepemc Territory," Twitter users also draw attention to the absence of a treaty in a particular region, indicating illegal dispossession of land from Indigenous peoples. Other toponymic identifiers focus on the theft and occupation of Indigenous lands with such modifiers as "stolen," "occupied," and "colonized." Some users locate themselves as "settlers" or "guests," drawing attention to their own positions in relation to both particular territories and the settler state.

Taken together, these examples highlight ways users leverage the free-form location profile field for resurgent and resistant anticolonial ends. We are interested here in the representational and infrastructural significance of how users take up toponymsfinding evidence that for Twitter users, location is not merely spatial. In the tiny space of the location profile field, users capture the relational, historical, political, culturolinguistic, legal, and cosmological nature of land and location. Such a rich representation makes plain by contrast the colonial nature of platform affordances which rely on structural categories for data gathering, management, analysis, and surveillance through sanctioned place names or GIS. The challenges we experienced in sorting, naming, and analyzing toponyms are in conflict with such managerial tactics and evidence a small, but welcome, reprieve from centralized surveillance and classification on social media.

\section{References}

apihtawikosis^an (Chelsea Vowel). 2016. Beyond territorial acknowledgments. Retrieved October 4, 2016 from http://apihtawikosisan.com/2016/09/beyond-territorial-acknowledgments/

Borra, E. \& Rieder, B. (2014). Programmed method: developing a toolset for capturing and analyzing tweets. Aslib Journal of Information Management, 66(3), 262-278.

Plantin, J.-C., Lagoze, C., Edwards, P. N., \& Sandvig, C. (2018). Infrastructure studies meet platform studies in the age of Google and Facebook. New Media \& Society, 20(1), 293-310.

Rogers, R. (2013). Digital methods. MIT press. 
Rose-Redwood, R., Alderman, D., \& Azaryahu, M. (2010). Geographies of toponymic inscription: new directions in critical place-name studies. Progress in Human Geography, 34(4), 453-470.

Snelgrove, C., Dhamoon, R. K., \& Corntassel, J. (2014). Unsettling settler colonialism: The discourse and politics of settlers, and solidarity with Indigenous nations. Decolonization: Indigeneity, Education \& Society, 3(2).

van Dijck, J., Nieborg, D., \& Poell, T. (2019). Reframing platform power. Internet Policy Review, 8(2). 